\title{
Antioxidant activity of the microalga Spirulina maxima
}

\author{
M.S. Miranda ${ }^{1}$, \\ R.G. Cintra, \\ S.B.M. Barros ${ }^{2}$ and \\ J. Mancini-Filho ${ }^{2}$
}

\author{
1Faculdade de Farmácia e Bioquímica, \\ Universidade Federal da Bahia, Salvador, BA, Brasil \\ ${ }^{2}$ Faculdade de Ciências Farmacêuticas, \\ Universidade de São Paulo, São Paulo, SP, Brasil
}

\section{Correspondence \\ J. Mancini-Filho \\ FCF, USP \\ Av. Prof. Lineu Prestes, 580 \\ Bloco 14 \\ 05508-900 São Paulo, SP \\ Brasil \\ Fax: 55 (011) 815-4410 \\ E-mail: jmancini@usp.br}

Research supported by CAPES and CNPq (No. 520456/95). Publication supported by FAPESP.

Received September 26, 1997 Accepted May 27, 1998

\section{Abstract}

Spirulina maxima, which is used as a food additive, is a microalga rich in protein and other essential nutrients. Spirulina contains phenolic acids, tocopherols and $\beta$-carotene which are known to exhibit antioxidant properties. The aim of the present study was to evaluate the antioxidant capacity of a Spirulina extract. The antioxidant activity of a methanolic extract of Spirulina was determined in vitro and in vivo. The in vitro antioxidant capacity was tested on a brain homogenate incubated with and without the extract at $37^{\circ} \mathrm{C}$. The $\mathrm{IC}_{50}$ (concentration which causes a $50 \%$ reduction of oxidation) of the extract in this system was $0.18 \mathrm{mg} / \mathrm{ml}$. The in vivo antioxidant capacity was evaluated in plasma and liver of animals receiving a daily dose of $5 \mathrm{mg}$ for 2 and 7 weeks. Plasma antioxidant capacity was measured in brain homogenate incubated for $1 \mathrm{~h}$ at $37^{\circ} \mathrm{C}$. The production of oxidized compounds in liver after $2 \mathrm{~h}$ of incubation at $37^{\circ} \mathrm{C}$ was measured in terms of thiobarbituric acid reactant substances (TBARS) in control and experimental groups. Upon treatment, the antioxidant capacity of plasma was $71 \%$ for the experimental group and $54 \%$ for the control group. Data from liver spontaneous peroxidation studies were not significantly different between groups. The amounts of phenolic acids, $\alpha$-tocopherol and $\beta$-carotene were determined in Spirulina extracts. The results obtained indicate that Spirulina provides some antioxidant protection for both in vitro and in vivo systems.

\section{Key words}

- Microalgae

- Antioxidant activity

- Spirulina maxima

- Phenolic compounds

- ß-Carotene

- $\alpha$-Tocopherol
Phytoplankton comprises organisms such as diatoms, dinoflagellates, green and yellow-brown flagellates, and blue-green algae. As photosynthetic organisms, these groups play a key role in the productivity of oceans and constitute the basis of the marine food chain. Among several alga genera, Spirulina and Chlorella deserve special attention due to their importance as human food and their in vitro and/or in vivo antioxidant potential (1). Spirulina algae are an important source of nutrients in the traditional diet of some populations of Africa and Mexico. These algae can be extensively grown to obtain a protein-rich material of alimentary use (foodstuff for diet complementation) or industrial use (blue pigments, emulsifiers, thickening and gelling agent). The chemical composition of Spirulina indicates that it has a high nutritional value due to a wide range of essential nutrients, such as vitamins, minerals and proteins (1). Moreover, it contains 
other components such as $\omega-3$ and $\omega-6$ polyunsaturated fatty acid, provitamins and phenolic compounds. In addition, these algae can be produced in large-scale systems (2).

There is a current worldwide interest in finding new and safe antioxidants from natural sources such as plant material to prevent oxidative deterioration of food and to minimize oxidative damage to living cells (3). Experimental and epidemiological evidence suggests the participation of free radicals in tissue damage and pathological processes such as cardiovascular disease and cancer $(4,5)$. The use of synthetic antioxidants has decreased due to their suspected activity as promoters of carcinogenesis as well as a general consumer rejection of synthetic food additives (6).

The role of dietary antioxidants and their potential benefits in health and disease have attracted great attention (7). Components with antioxidant activities can be found in only a few species of algae (8). Although the occurrence of phenolic compounds in plants is well known and these groups of compounds possess antioxidant activity in biological systems (9), the antioxidant characteristics of algae are poorly known. Some studies reported that cancer was prevented by alga extracts $(10,11)$, because of their antioxidant properties (10).

The objective of the present experiment was to evaluate the influence of a Spirulina maxima extract on lipid peroxidation. Methanolic extracts were used in in vitro and in vivo tests of antioxidant activity. Also, $\beta-$ carotene, $\alpha$-tocopherol and phenolic acid levels in the alga extract were determined because of the antioxidant activity of these compounds.

Spirulina was obtained from the Oceanographic Institute of the University of São Paulo (Brazil) and cultivated using Paoletti's culture medium (12) in the laboratory under controlled conditions of light and temperature $(5,000$ lux, $14 \mathrm{~h}$ light and $10 \mathrm{~h}$ dark, at $20^{\circ} \mathrm{C}$ ). The cultures were mantained for ten days and stopped $24 \mathrm{~h}$ after exponential algal growth phase. Lyophilized algae were extracted with ethyl ether and the residue was extracted with methanol. The methanol extract ( $800 \mathrm{mg}$ of dried residue $/ \mathrm{ml} 50 \mathrm{mM}$ sodium phosphate buffer, $\mathrm{pH}$ 7.4) was used for the antioxidant assays. $\beta$-Carotene, $\alpha$ tocopherol, phenolic acids and antioxidant activity were determined in the dried residue.

In vitro antioxidant activity. Brain homogenate with Spirulina extract added (experimental) or not (control) was used to quantify lipid peroxidation. The brain of adult male rats (about $300 \mathrm{~g}$ ) was isolated after perfusion with $0.9 \%$ saline. Brain tissue was homogenized in $0.1 \mathrm{M}$ phosphate buffered saline, $\mathrm{pH} 7.0(1: 4, \mathrm{v}: \mathrm{v})$ in a Potter homogenizer. The supernatant $(800 \mathrm{~g}$ for 10 min, diluted 1:3 with the buffer) was employed in spontaneous lipid peroxidation tests according to Stocks et al. (13). Buffer (control) or Spirulina methanolic extract (10 to $500 \mu \mathrm{g}$ ) in buffer was added. Following incubation for $1 \mathrm{~h}$ at $37^{\circ} \mathrm{C}, 1-\mathrm{ml}$ samples were mixed with $1 \mathrm{ml}$ of $5 \%$ trichloroacetic acid (TCA) and centrifuged at $900 \mathrm{~g}$ for 15 min. These supernatants $(1 \mathrm{ml})$ were added to $0.67 \%$ thiobarbituric acid (TBA) $(1 \mathrm{ml})$ and boiled for $20 \mathrm{~min}$. The thiobarbituric acid reactive substances (TBARS) were determined by spectrophotometry at $535 \mathrm{~nm}$. Antioxidant activity was calculated as percent inhibition of peroxidation relative to control. The concentration of extract causing a $50 \%$ reduction in lipid oxidation $\mathrm{IC}_{50}$ was then calculated (14).

In vivo antioxidative activity. Twentyfour adult male Wistar rats weighing 250$270 \mathrm{~g}(261.0 \pm 8.7)$ were used in this study. The animals were given Purina ${ }^{\circledR}$ rat chow and water ad libitum. Rats were housed 6 to a cage, on a 12-h light cycle and under controlled temperature. The experimental group (12 animals) received by gavage $1 \mathrm{ml}$ of Spirulina extract resuspended in $0.1 \mathrm{M}$ phosphate buffer, pH $7.4(5 \mathrm{mg} / \mathrm{ml})$, and the 
control group (12 animals) received only the buffer by gavage. After ether anesthesia the rats were killed by decapitation and plasma was obtained using heparin as anticoagulant. Livers and plasma of control and treated animals were obtained after 2 (6 animals) or 7 weeks (6 animals) and the liver was homogenized with $50 \mathrm{mM}$ sodium phosphate buffer, pH 7.4 (1:4). Antioxidative activity was determined as a reduction in spontaneous lipid peroxidation of brain homogenate by the addition of plasma (13). Brain homogenates with plasma were incubated for $1 \mathrm{~h}$ at $37^{\circ} \mathrm{C}$. Lipid peroxidation was evaluated after incubation for $2 \mathrm{~h}$ at $37^{\circ} \mathrm{C}$. Malonaldehyde (MDA) was measured as TBARS production at $535 \mathrm{~nm}$ using $\mathrm{E}=1.56 \times 10^{-5} \mathrm{M}^{-1}$ $\mathrm{cm}^{-1}$. Liver peroxidation was normalized to protein content measured by the method of Lowry et al. (15). The results are reported as percent inhibition of oxidation of brain homogenate, and $\mu \mathrm{mol}$ TBARS/mg protein for plasma and hepatic homogenate.

Phenolic compounds. A spectrophotometric method was used to determine the total phenolic compounds with catechin as internal standard (16). Phenolic acid extraction was performed by the method of Dabrowski and Sosulski (17) and the phenolic acid analyses were carried out using a CG 500 model gas chromatograph equipped with a flame ionization detector and connected to a CG 300 computerized integrator. A capillary polymethylphenylsiloxan-FI 95 (CG do Brasil S/A, São Paulo) column was used. An initial temperature of $150^{\circ} \mathrm{C}$ was used for $3 \mathrm{~min}$, followed by increments of $5^{\circ} \mathrm{C} / \mathrm{min}$ up to $300^{\circ} \mathrm{C}$. Nonconjugated and total phenolic acids were identified on the basis of the relative retention time of their derivatives compared with the standard phenolic acids.

$\beta$-carotene. The $\beta$-carotene content of Spirulina algae and of the methanolic extract was determined by absorption spectroscopy with a Perkin-Elmer Lambda 3B spectrophotometer equipped with an $\mathrm{R} 100 \mathrm{~A}$ re- corder. B-Carotene was quantified at 447 $\mathrm{nm}$, using $\mathrm{E}^{1 \%}{ }_{1 \mathrm{~cm}}=2592^{\mathrm{cm}-1}$ for $\beta$-carotene (18).

$\alpha$-Tocopherol. $\alpha$-Tocopherol content of the methanolic extract was determined by a high pressure liquid chromatographic (HPLC) method. A 20- $\mu 1$ sample was injected with an SIL 10A automatic injector (Shimadzu, Tokyo) with a class LC-10 software package, and an LC work station chromatographic system (Shimadzu Corp.) with an electrochemical detector L-ECD-6A and a reverse-phase $\mathrm{C} 18$ Cgnucleosil (CG do Brasil S/A) column. The mobile phase was isocratic with the methanol:acetonitrile:chloroform mixture $(35: 35: 30, \mathrm{v} / \mathrm{v})$ with a flow rate of $1 \mathrm{ml} / \mathrm{min}$. Tocopherol was determined with an external standard using a multiple level calibration curve (19).

Statistical analysis. Analysis of variance and the Tukey test were used to evaluate the results, with the level of significance set at $\mathrm{P}<0.05$.

The $\beta$-carotene and total tocopherol content of Spirulina in the methanolic extract was $27.5 \mathrm{mg} / \mathrm{l}$ and $18 \mathrm{mg} / \mathrm{l}$, respectively. The total phenolic compounds were $96.3 \mathrm{mg} / \mathrm{l}$, a value corresponding to $15.4 \mathrm{mg}$ total phenolics in $1 \mathrm{~g}$ of alga dry matter from the methanolic extract. The phenolic compounds salicylic, trans-cinnamic, synaptic, chlorogenic, quimic and caffeic acids found in the methanolic alga extract may be responsible for its antioxidant activity, individually or by a synergistic action (3). The phenolic compounds chlorogenic and caffeic acids present in the Spirulina extract were more efficient antioxidants than other acids in lard (20); Ho (9) reported that these acids have a potential preventive action against cancer. Tutour (19) reported an antioxidant ability of extracts (methanol/chloroform) of several marine algae in sunflower oil stored at $75^{\circ} \mathrm{C}$. Our experimental extract also showed $45 \%$ antioxidant ability in oil (data not shown). Sakata et al. (8) reviewed the antioxidants from marine organisms, including alga ex- 
Figure 1 - Antioxidant activity of a methanolic extract of Spirulina. Brain homogenate with the Spirulina extract added was incubated at $37^{\circ} \mathrm{C}$ for $1 \mathrm{~h}$ and inhibition of TBARS formation determined. The $\mathrm{IC}_{50}$ value of 180 $\mu \mathrm{g}$ was calculated from triplicate measurements.

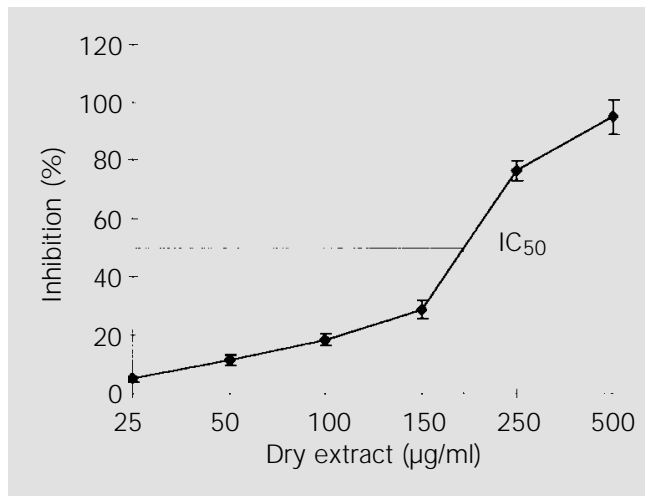

Table la - Reduction of thiobarbituric acid reactant substances (TBARS) by plasma obtained from control and Spirulina extract-treated rats.

The antioxidant activity is the inhibition of TBARS produced in brain homogenate (prepared from adult rats without any treatment) by plasma of the experimental or control group: (TBARS in the brain homogenate system with rat plasma added/ TBARS in the brain homogenate system without plasma) $x$ 100. The experimental group received the methanolic extract of Spirulina ( $5 \mathrm{mg} / \mathrm{d}$ ) resuspended in buffer for 2 or 7 weeks; the same volume of phosphate buffer was given to the control group. Data are reported as means \pm SD for 6 rats in each group. ${ }^{*} \mathrm{P}<0.05$ compared to control.

\begin{tabular}{lcc}
$\begin{array}{l}\text { Treatment } \\
\text { (weeks) }\end{array}$ & $\begin{array}{c}\text { Control } \\
(\%)\end{array}$ & $\begin{array}{c}\text { Experimental } \\
(\%)\end{array}$ \\
\hline 2 & $74.2 \pm 7.4$ & $97.0 \pm 4.2^{*}$ \\
7 & $54.0 \pm 7.0$ & $71.4 \pm 12.9 *$
\end{tabular}

Table $1 b$ - TBARS produced in livers of control and experimental animals.

The experimental group received the methanolic extract of Spirulina ( $5 \mathrm{mg} / \mathrm{d}$ ) resuspended in buffer for 2 or 7 weeks; phosphate buffer was given to the control group. Data are reported as means \pm SD for 6 rats in each group.

\begin{tabular}{lcc}
\hline $\begin{array}{l}\text { Treatment } \\
\text { (weeks) }\end{array}$ & $\begin{array}{c}\text { Control } \\
(\mu \mathrm{mol} / \mathrm{mg} \text { protein) }\end{array}$ \\
\hline 2 & $2.52 \pm 0.17$ & $2.61 \pm 0.16$ \\
7 & $3.47 \pm 0.34$ & $3.13 \pm 0.39$
\end{tabular}

tracts from different species. Many species of algae showed strong antioxidant ability; degradation products of chlorophyll and compounds in the lipid fraction were defined as the active principles in cultures of Euglena gracilis Z (21). The ethanolic extract of Spirulina shows a synergistic effect of phenolic compounds and 13-cis-retinoic acid in preventing lipid peroxidation (11).

Peroxidation of rat brain homogenate was inhibited by almost $95 \%$ with $0.5 \mathrm{mg}$ of the Spirulina-containing methanolic extract. Figure 1 shows that the $\mathrm{IC}_{50}$ was $180 \mu \mathrm{g}$. The antioxidant activity depends on the chemical characteristics of each compound and the model system used. A given compound can show antioxidant activity in brain homogenate but fail to give a clear response when provided in the diet or given by gavage, because several factors can be interfering in vivo such as absorption, transport and metabolism of the drug by the organism.

The plasma and liver homogenates of Spirulina-treated animals were used to evaluate the antioxidant ability of the extract in vivo. The TBARS data obtained with brain homogenate revealed less intense plasma peroxidation in treated rats than in the control group. After 2 and 7 weeks of treatment the plasma antioxidant capacity was 97 and $71 \%$ for the experimental groups and 74 and $54 \%$ for the control groups (Table 1a), although TBARS production from liver homogenates did not differ between control and extract-treated groups, as shown in Table 1b.

Protection against cancer and aging has been attributed to the components of Spirulina alga with an antioxidant action $(10,11)$, among them $\beta$-carotene (10). Schwartz and Shklar (11) showed that the alga extract was more effective on hamster cancer regression than $\beta$-carotene alone and concluded that there is a possible synergistic effect of the extract components since there was evidence that components other than $\beta$ - 
carotene have a decisive action in the oxidation inhibition. This consideration is relevant since the experimental extract contains less $\beta$-carotene than integral algae. However, the possibility exists that there are other unknown constituents in algae with antioxidative activity that might enhance the antioxidant synergism (8). Tutour (19) proposed that some compounds such as vitamin $\mathrm{C}$, phenols, amines and phospholipids from algae could regenerate vitamin $\mathrm{E}$. In one of his studies, this investigator identified the effective components of Laminaria digitata and Himanthalia elongata in order to clarify the mechanism of antioxidant synergism.

The data about the antioxidant activity of plasma presented in Table 1a suggest that antioxidant compounds are present in the methanolic extract of Spirulina which are absorbed and could be used to prevent oxidation. The TBARS data obtained for liver homogenate (Table 1b) showed a trend to lower level of these substances which, however, was not statistically different after seven weeks of Spirulina extract treatment.

\section{References}

1. Dillon J C \& Phan PA (1993). Spirulina as source of protein in human nutrition. Bulletin de I'Institut Oceanographique, 12: 103-107.

2. Pascaud M (1993). The essential polyunsaturated fatty acids of Spirulina and our immune response. Bulletin de I'Institut Oceanographique, 12: 49-57.

3. Pratt DE (1992). Natural antioxidants from plant material. In: Huang MT, Ho CT \& Lee CY (Editors), Phenolic Compounds in Food and their Effects on Health. II. American Chemical Society, Washington, 54-71 (ACS Symposium Series, 507).

4. Halliwell B \& Gutteridge J MC (1989). Free Radicals in Biology and Medicine. 2nd edn. Clarendon Press, Oxford, 299-357.

5. Kok FJ , Van Poppel G, Melse J, Merheul E, Schouten EG, Kruyssen EH \& Hofman A (1990). Antioxidant and polyunsaturated acids have a combined association with coronary atherosclerosis. Atherosclerosis, 86: 85-90.

6. Namiki M (1990). Antioxidants/antimutagenics in food. CRC Critical Reviews in Food Science and Nutrition, 29: 273-300.

7. Kehrer J P \& Smith CV (1994). Free radical in biology: sources, reactivities, and roles in the etiology of human disease. In: Frei B (Editor), Natural Antioxidants in Human Health and Disease. Academic Press, San Diego, 25-62.

8. Sakata K, Yamamoto $\mathrm{K} \&$ Watanable N (1992). Antioxidative compounds from marine organisms. In: Ho CT, Osawa T, Huang MT \& Rose RT (Editors), Food Phytochemicals for Cancer Prevention. II. American Chemical Society, Washington, 165-182 (ACS Symposium Series 547).

9. Ho CT (1992). Phenolic compounds in food: an overview. In: Huang MT, Ho CT, $\&$ Lee CY (Editors), Phenolic Compounds in Food and their Effects on Health. II. American Chemical Society, Washington, 2-7 (ACS Symposium Series, 507).

10. Fedkovic $Y$, Astre $C$, Pinguet $F$, Gerber $M$, Ychou M \& Pujol H (1993). Spinuline and cancer. Bulletin de I'Institut Oceanographique, 12: 117-120.

11. Schwartz J \& Shklar G (1987). Regression of experimental hamster cancer by betacarotene and alga extract. J oumal of Oral and Maxillofacial Surgery, 45: 510-515.

12. Waine PR (1996). Experiments in the large scale culture of the larvae of Ostrea edulis. Fishery Investigation, 25: 1-53.

13. Stocks J, Guteridge J MC, Sharp RJ \& Dormandy TL (1974). Assay using brain homogenate for measuring the antioxidant activity of biological fluids. Clinical Science and Molecular Medicine, 47: 215222.

14. Palozza P \& Krinsky N (1991). The inhibition of radical-initiated peroxidation of microssomal lipids by both $\alpha$-tocopherol and B-carotene. Free Radicals in Biology and Medicine, 11: 407-414.

15. Lowry $\mathrm{OH}$, Rosebrough $\mathrm{NJ}$, Faar $\mathrm{AL} \&$
Randall RJ (1951). Protein measurement with folin phenol reagent. J ournal of Biological Chemistry, 193: 265-275.

16. Swain T \& Hillis WE (1959). The phenolic constituents of Prunus domestica I. The quantitative analysis of phenolic constituents. J ournal of the Science of Food and Agriculture, 10: 63-68.

17. Dabrowski KJ \& Sosulski FW (1984). Quantification of free and hydrolizable phenolic acids by capillary gas-chromatography. J ournal of Food Science and Chemistry, 32: 123-127.

18. Almeida L \& Penteado MV (1988). Carotenoids and provitamin A value of white Brazilian sweet potatoes (Iponema batata Lam). J oumal of Food Composition and Analysis, 1: 314-352.

19. Tutour B (1990). Antioxidant activity of alga extracts, synergistic effect with vitamin E. Phytochemistry, 29: 3759-3765.

20. Marinova EM \& Yanishlieva N (1992). Inhibited oxidation of lipids. II. Comparison of the antioxidative properties of some hydroxy derivatives of benzoic and cinnamic acids. Fat Science Technology, 94: 428-430.

21. Takeyama H, Kanamaru A, Yoshimo $Y$ Katuta H, Kawamura $Y$ \& Matsunaga $T$ (1997). Production of antioxidant vitamins, beta-carotene, vitamin $\mathrm{C}$, and vitamin $\mathrm{E}$, by two step culture of Euglena gracilis $Z$. Biotechnology and Bioengineering, 53: 185-190. 